Año 16, Vol. 11, número 21, agosto-diciembre 2021

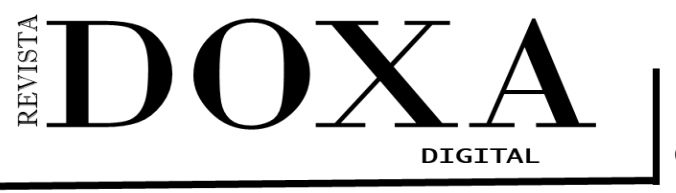

elSSN: 2594-2786
Sección: Dossier

Ponencia presentada el 1 de junio del 2021

DOI: $10.52191 /$ rdojs.2021.237

Pág.: 195-211

Ponencia presentada en la mesa 5:

"Políticas públicas, sociedad y gobierno"

Primer Coloquio de Estudiantes y Egresados de Licenciatura y Posgrado

Ciudad Juárez, México 1 y 2 de junio 2021

\title{
Circulación de vehículos con placas informales en Ciudad Juárez, Chihuahua
}

\section{Circulation of vehicles with informal license plates in Ciudad Juárez, Chihuahua}

\author{
Cynthia Ivonne Quiñones Pacheco* e Ignacio Camargo González **
}

\section{RESUMEN}

La expedición de placas no oficiales para vehículos comenzó hace años, esta estrategia fue implementada por los vendedores de autos seminuevos para así poder censarlos y esperar alguna campaña de regularización vehicular, en la cual se pudieran regularizar todos los vehículos extranjeros que ingresaron a Ciudad Juárez, así como también por asociaciones afiliadoras de vehículos de procedencia extranjera..

La investigación observará desde un punto de vista objetivo el tema de la regularización vehicular en Ciudad Juárez, la cantidad de personas que no contribuyen con el impuesto por tener un vehículo automotor, que portan placas informales, aunado a lo anterior los motivos que se tiene para comprar este tipo de vehículos de procedencia extranjera, mismos que son difíciles o imposibles de llevar a cabo el trámite de la legalización correspondiente.

También se pretende responder el porqué de la falta de implementación de política pública es este fenómeno social, y si existe alguna relación de poder entre vendedores de las palcas rojas y un ente gubernamental, situación que permita seguir con la compra-venta del tipo de placas no oficiales mencionadas con antelación

PALABRAS CLAVE: Placas no oficiales, placas informales, legalización vehicular, relación de poder.

* Autor para correspondencia. Licenciada en derecho, egresada de la Universidad Autónoma de Ciudad Juárez, actualmente estudiante de la maestría en Gobierno y Participación Ciudadana en la Universidad Autónoma de Chihuahua. Contacto: cynthia.iqp@gmail.com.

** Doctor en Ciencias Sociales profesor de tiempo completo de la Facultad de Ciencias Políticas y Sociales, de la Universidad Autónoma de Chihuahua. Contacto: icamargo0202@yahoo.com.mx 
Año 16, Vol. 11, número 21, agosto-diciembre Sección: Dossier

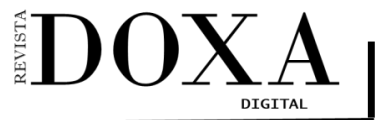

pISSN: 2395-8758 eISSN: 2594-2786
DOI: $10.52191 /$ rdojs.2021.237

Pág.:195-211
Cynthia Ivonne Quiñones Pacheco y

Ignacio Camargo González

Circulación de vehículos con placas informales...

\section{Introducción}

\section{Antecedentes}

La implementación de las placas en vehículos, no es una creación reciente, sino que se remonta a muchos años atrás, fueron creadas para la identificación de vehículos y para tener mayor control de los mismos en los diferentes países en donde fueron puestos en práctica dichos actos, tal como lo menciona Huerta de Ávila (2014) en su artículo llamado Control Vehicular en México: El programa del Registro Público Vehicular: "el marcaje fue realizado originalmente por los fabricantes desde 1954, en el que países como Estados Unidos de América y Europa, comenzaron a generar un Número de Identificación Vehicular (NIV)..."

En México no era obligatorio sino hasta el año de 1997, cuando se generó la Norma Oficial Mexicana. La primera Norma respecto a la generación del Número de Identificación Vehicular fue creada el 1998 (NOM-131-SDFI-1998) a cargo de la Secretaría de Comercio y Fomento Industrial, en el 2004, se entrega a la Secretaría de Seguridad Pública (NOM-001-SSP-2008) la asignación y colocación del NIV.

El aumento en los vehículos que se encuentran en circulación es causado por todos aquellos vehículos extranjeros provenientes de Estados Unidos, el problema surge cuando esos automóviles no son regularizados por medio de la importación correspondiente, cabe mencionar lo expuesto por Parra (2015) quien manifiesta que se redujo alrededor de un 54\% (cincuenta y cuatro por ciento) el cupo de importación de automóviles, y en relación a este dato es conveniente exponer que según Cruz-Rivera y Ertel (2008), existen dos causas que propician el fenómeno de los vehículos que circulan de manera ilegal, el primero consiste en la falta de recursos económicos para poder adquirir un automóvil nuevo o usado que sea nacionalizado y la segunda causa es que los vehículos provenientes de Estados Unidos, en su mayoría, son introducidos a México con un permiso temporal, pero terminan permaneciendo de forma definitiva en el país.

Tan solo en el año 2014 se importaron a México 455,372 vehículos proveniente de Estados Unidos, por lo cual se calcula que se han acumulado alrededor de 7.5 millones de estos automóviles circulando en todo el país, de acuerdo a lo expuesto por Ollivier Fierro (2018).

Así mismo corresponde mencionar que es muy complicado recopilar o adquirir información estadística cuantitativa, mejor dicho, la cantidad específica de automóviles de procedencia extranjera internados en el país, en especial en Ciudad Juárez, toda vez que no existe padrón alguno que tenga el control necesario de la cantidad de vehículos circulando con este tipo de placas y engomados informales, podría tenerse la noción, sin embargo, no un número con exactitud.

\section{Planteamiento del problema}

La presente investigación está ubicada en el efecto de la circulación de vehículos con placas informales en Ciudad Juárez, se desconoce la motivación de las personas que son propietarias de vehículos de procedencia extranjera, que solamente portan una placa no oficial para circular por la ciudad, así como también cuales son las causas de que no se aplique la política pública correspon- 
Año 16, Vol. 11, número 21, agosto-diciembre

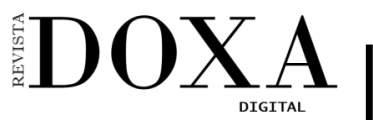

pISSN: 2395-8758 eISSN: 2594-2786
Sección: Dossier

DOI: $10.52191 /$ rdojs.2021.237

Pág.:195-211
Cynthia Ivonne Quiñones Pacheco y

Ignacio Camargo González

Circulación de vehículos con placas informales...

diente respecto a estos vehículos en circulación. Es preciso determinar también, si existe alguna relación de poder entre los vendedores de las placas informales, asociaciones afiliadoras y con quién existe la mencionada relación de poder, que permite la venta y circulación de las mencionadas.

\section{Objetivo general y específicos}

Analizar los factores que determinan el funcionamiento del mercado informal de las placas no oficiales, relacionar la ausencia de implementación de política pública en este fenómeno social con alguna relación de poder entre diversos actores, esto en Ciudad Juárez Chihuahua en el periodo 2017-2021.

Describir los motivos por los cuales los ciudadanos optan por portar placas no oficiales en sus vehículos; especificar los aspectos económicos y políticos que involucra la comercialización de las placas informales; analizar la falta de implementación de política pública en el fenómeno de las placas informales no oficiales y su impacto en la sociedad.

\section{Justificación}

La circulación de vehículos con placas no oficiales, es un acontecimiento que surgió desde años atrás, y que en el año 2021 sigue ocurriendo, dicho fenómeno social tiene consecuencias en Ciudad Juárez, con motivo de que son automóviles que circulan de forma ilegal en la ciudad, por lo cual es necesario investigar las causas de que no se lleve a cabo la acción necesaria para el control de la expedición de placas no oficiales, aunado a lo anterior, es de suma importancia el observar el trasfondo de este fenómeno social, cuáles son las causas que lo han alimentado, como ha sido su evolución, quienes son los actores involucrados y su forma de operar. Lo anterior para estar en condiciones de describir, explicar y comprender de manera profunda el comportamiento de los vendedores, compradores y personas con relación de poder que se involucren, para así, aclarar el panorama del citado fenómeno social, sus motivaciones y evolución. La investigación descrita con antelación, trae consigo el beneficio de aportar nueva información del tema expuesto, ya que actualmente no hay estudios previos enfocados en los factores determinantes del funcionamiento del mercado informal de las placas no oficiales y de la ausencia de implementación de política pública en Ciudad Juárez.

\section{Pregunta de investigación}

¿Cuáles son los factores determinantes del funcionamiento del mercado informal de las placas no oficiales, y de la ausencia de implementación de política pública en Ciudad Juárez en el periodo 2017 al 2021 ?

\section{Hipótesis}

La población que es propietaria de un vehículo que porta placas informales no oficiales, accede a tener estos vehículos de procedencia extranjera por el sencillo proceso de adquisición, así como por el bajo costo del vehículo, y las responsabilidades que se omiten en cuanto a impuestos se 
Año 16, Vol. 11, número 21, agosto-diciembre

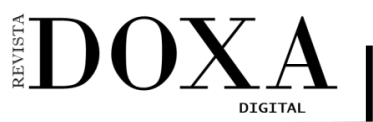

pISSN: 2395-8758 eISSN: 2594-2786
Sección: Dossier

DOI: $10.52191 /$ rdojs.2021.237

Pág.:195-211
Cynthia Ivonne Quiñones Pacheco y

Ignacio Camargo González

Circulación de vehículos con placas informales...

trata, lo anterior con motivo de que es un automóvil no legalizado. La causa de que se permita la compra-venta de las placas informales, es la existencia de una relación de poder con algún actor o ente del gobierno, derivado de esto, no existe la sanción correspondiente a dichos actos y no se implementa la política pública que se adecua al fenómeno social.

\section{Limitaciones}

En el trabajo de investigación existen distintas limitaciones para poder recabar la información necesaria y la realización de trabajo de campo, en primer lugar, está la pandemia y la contingencia del COVID-19, la falta de estudios previos que hagan referencia al tema de investigación y por último el corto tiempo con el que se cuenta para realizar el trabajo.

\section{Marco teórico, epistemológico y contextual}

\section{$\underline{\text { Registro público vehicular }}$}

Es la acción de tener un vehículo de manera legal en el país de México, aunado a esto, si el automóvil ya está debidamente importado, el siguiente paso es acudir a la dependencia correspondiente a tramitar las placas metálicas que contienen letras y números, mismos que son para la identificación y control de los vehículos que circulan al país, derivado de dicho trámite, año con año se realiza el pago de un impuesto, fijado por el gobierno, por el hecho de ser propietario de un vehículo.

\section{Número de identificación vehicular}

La identificación de vehículo automotor está basada en un conjunto de características que permiten identificar al vehículo desde su aspecto general, como lo es la estructura exterior, marca, color, año de fabricación, alfanuméricos de chasis, motor, placa del fabricante y detalles respecto a la autenticidad del producto instaladas de origen en el automóvil, todas estas características son las que lo diferencian de todos los demás. El número de identificación vehicular (NIV) o número VIN (del inglés Vehicle Identification Number) permite la identificación exacta de todo vehículo automotor.

\section{Matriculación vehicular}

La matriculación vehicular, es un proceso en el cual participan varias dependencias gubernamentales. En este proceso el propietario del vehículo está obligado a pagar diversos impuestos señalados en la ley correspondiente, que rige el trámite de la matriculación vehicular.

\section{Autos chocolate}

De acuerdo a lo expuesto por Alarcón Gil (2014) estos son automóviles ilegales que circulan prácticamente sin identificación, son conocidos como "autos chocolate", mismos que lo largo de la frontera norte de México es común observarlos, son automóviles de origen estadounidense que son introducidos a México, pero no cuentan con los permisos de tenencia regulados por el Estado mexicano. 
Año 16, Vol. 11, número 21, agosto-diciembre Sección: Dossier

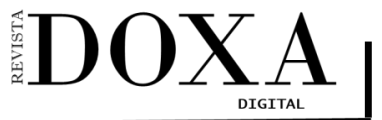

pISSN: 2395-8758 eISSN: 2594-2786
DOI: $10.52191 /$ rdojs.2021.237

Pág.:195-211
Alejehidrbubbodsiñanes Pacheco y

FaracticaGsfonango taosocátedad.

Circulación de vehículos con placas informales...

\section{Mercado informal de compra venta de autos usados}

La compraventa de vehículos usados es una de las actividades más informales que se lleva a cabo en diversos lugares del mundo, en donde el comprador y el vendedor efectúan un contrato en donde se estimulan y adquieren obligaciones para cada una de las partes, se formaliza con la legalización y otorgamiento de un contrato de compra venta, mismo que culmina con el intercambio del vehículo y del dinero (Castro Cobo, 2014). Los vehículos usados que son motivo de compra venta, en su mayoría son autos usados provenientes del extranjero, especialmente de Estados Unidos, Arévalo Avecillas (2009) menciona que la alternativa de abrir las fronteras para la incursión del mercado de vehículos usados, constituye el origen del mercado que puede llegar a ser explotado, ya que actualmente los individuos de los estratos socioeconómicos medios bajos y bajos no están en posibilidades de acceder a este tipo de bienes.

\section{Importación de vehículos}

En cuanto a la importación compete Merchán Galarza (2018) establece que la importación radica en la compra de bienes o servicios que representa una salida de divisa para el Estado y una entrada de bienes o productos, por lo cual la importación puede ser definida como "la acción de ingresar mercaderías extranjeras al país cumpliendo con las formalidades y obligaciones aduaneras, dependiendo del Régimen de importación al que se haya sido declarado." (ADUANA DEL ECUADOR SENAE, 2017).

Ya que existe una gran cantidad de autos de importación existen diversas empresas importadoras de vehículos usados en las cuales su actividad principal es la compra venta, importación, exportación, almacenamiento, distribución, mantenimiento de vehículos automotores de todo tipo, repuestos y accesorios para remodelación y venta (Chipix Notz, 2014).

\section{$\underline{\text { Regularización vehicular }}$}

Martínez Rodríguez y Kuppusamy (2006) argumentan que en México la regularización de vehículos de procedencia extranjera, en los últimos 25 años reporta que ha habido un total de 14 programas (hasta el 2001), donde los primeros acuerdos únicamente permitían la regularización para los propietarios avecindados en las zonas fronterizas.

\section{Incremento del parque vehicular}

Según lo expuesto por Favia (2020), en un periodo de 10 años, de 2009 a 2019, el parque vehicular que se encuentra en circulación en Ciudad Juárez ha aumentado en un 31.38 por ciento, una cantidad alarmante desde la perspectiva de Néstor Acosta, director de la asociación ambientalista Juárez Limpio. De acuerdo con el Informe de Movilidad y Transporte en Juárez 2020, realizado por la organización civil Plan Estratégico de Juárez (PEJ), en el mismo periodo mencionado anteriormente los vehículos registrados pasaron de 444 mil 970 a 586 mil 171 unidades, lo que representa un incremento promedio de 11 mil 236 vehículos por año.

Urbizu-González, Andrade de-Limas, De la Garza- Requena y Macias-Hernández (2014), manifies- 
Año 16, Vol. 11, número 21, agosto-diciembre Sección: Dossier

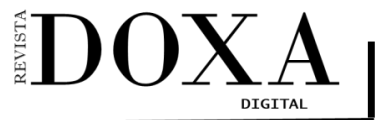

pISSN: 2395-8758 eISSN: 2594-2786
DOI: 10.52191/rdojs.2021.237

Pág.:195-211
Cynthia Ivonne Quiñones Pacheco y

Ignacio Camargo González

Circulación de vehículos con placas informales...

tan que, en el estado de Tamaulipas, la cantidad de automóviles se incrementó en más del $30 \%$ y específicamente, para el municipio de Victoria, el aumento fue en un $88 \%$, alcanzando los 110,469 vehículos registrados legalmente (INEGI, 2011). Sin embargo, y debido a la apertura de la importación de vehículos usados de los Estados Unidos, una porción del parque vehicular que circula en Victoria, son dichos automóviles, que de acuerdo con la Unión Campesina Democrática (2010) son alrededor de 7,500 vehículos. Datos que alcanzan una proporción en la relación vehículopoblación: dos habitantes por vehículo.

\section{Corrupción y contrabando}

La relación entre corrupción y crecimiento económico depende del marco institucional, se supone que cuando las instituciones no funcionan de manera adecuada la corrupción puede remplazar la carencia de funciones institucionales, por el contrario, si las instituciones funcionan correctamente la corrupción actúa en detrimento de la producción, al obstruir el buen funcionamiento de las primeras (Ramírez y López, 2013).

Barrera-Enderle (2018) considera que la habilidad de los fronterizos para introducir ilegalmente automóviles para su uso personal, y después la proliferación de bandas del crimen organizado que se dedicaron también a dicha actividad, obligará a las autoridades federales a modificar constantemente sus regulaciones en la materia. En pocas palabras, los esfuerzos del gobierno federal por fortalecer su presencia y controlar sus aduanas fronterizas no será suficiente para evitar que los fronterizos dejaran de sacar ventaja de su posición geográfica y de sus vínculos trasnacionales.

Una de las estrategias más empleadas para introducir ilegalmente automóviles al país consistió en que algún ciudadano estadounidense ingresaba a México por vía terrestre conduciendo su coche, haciéndose pasar como turista. Esta práctica ilegal data de al menos 1930.

Aller Vera (2016) menciona que la incautación de vehículos por delito de contrabando a los compradores de buena fe es un problema jurídico social que afecta el derecho de propiedad y tiene graves consecuencias en la economía de las personas que involuntariamente se ven comprometidas en este problema.

Las personas a quienes se les incautan los vehículos por presunto delito de contrabando son generalmente compradores que figuran después del segundo comprador en el tracto sucesivo.

El Secretario de Seguridad Pública Estatal, Emilio García Ruíz, manifestó que van 300 carros decomisados por todas las corporaciones, hizo hincapié en que van a retirar de las calles a todos los vehículos sin placas, sin importar año y modelo.

Los operativos seguirán por lo que pide a la ciudadanía no exponerse y no utilizar estos carros (Tovar, 2020).

\section{Placas oficiales y sanciones}

Gutiérrez y Frydson (2011) definen a las placas vehiculares como el registro que usan los vehículos automotores para su identificación y circulación legal en todo el territorio nacional. Todas 
Año 16, Vol. 11, número 21, agosto-diciembre Sección: Dossier

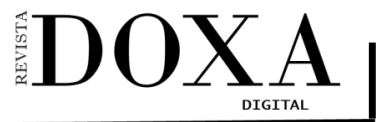

pISSN: 2395-8758 eISSN: 2594-2786
DOI: 10.52191/rdojs.2021.237

Pág.:195-211
Cynthia Ivonne Quiñones Pacheco y

Ignacio Camargo González

Circulación de vehículos con placas informales...

las placas de identificación vehicular deben ser de una lámina metálica rectangular que deben cumplir con las normas de seguridad, recubrimiento y reflectancia que determine la autoridad correspondiente. Su diseño es único para todo el país, las letras y números, se conforman por letras y números.

En cuanto a retirar vehículos de circulación por varias causas, en el estado de Chihuahua el gobernador expresó que dicha decisión fue tomada por el Grupo de Coordinación para la Construcción de la Paz, por esta situación se exhortó a la población a no arriesgar su patrimonio usando o adquiriendo unidades irregulares. Aunado a lo anterior el titular del Ejecutivo estatal propuso a la ciudadanía a que no conduzca automóviles sin placas oficiales, al ser un delito (Chihuahua, 2020).

Vargas (2020) publicó que oficialmente se insistió en que los operativos para decomisar vehículos sin placas iniciarían determinado día, ninguna de las autoridades que intervendrían en los operativos, no informó sobre algún aseguramiento, ni se observaron en las calles que se estuvieran dando, según recorridos de El Diario en los alrededores de la ciudad.

Mandos de las corporaciones informaron de manera extraoficial que no hubo instrucciones de desplegar vigilancia especial en torno a estas acciones y coincidieron en que, tras el anuncio público que se hizo al respecto, el aforo ordinario de vehículos había disminuido en la ciudad, en el supuesto de que este tipo de autos se escondieron por los propietarios.

Pero el fiscal de la Zona Norte, Jorge Nava López, dijo ayer que no hay marcha atrás en los operativos, pero que se iniciaría con una campaña de concientización para hacer saber a la ciudadanía en qué delitos se puede incurrir al poseer un vehículo internado de manera irregular al país o con placas sobrepuestas.

\section{Vehículos extranjeros (casos similares a ciudad Juárez)}

Una situación similar a la que se vive día con día en Ciudad Juárez, sucede en Colombia, así lo manifiesta Escalante Olarte y Hernández Santiago (2018), toda vez que en Colombia la presencia de vehículos con matrícula venezolana fue constante en las zonas de la frontera que limitaban con el país vecino antes de 2015. San José de Cúcuta, ciudad fronteriza en Colombia, presenta en su parque vehicular un mayor número de automóviles y motocicletas con placas de Venezuela, por lo cual la industria automotora se ha visto perjudicada por la compra masiva de vehículos venezolanos, los que se encuentran a un menos costo en relación con los precios nacionales.

El trámite en el ámbito nacional para la internación de los vehículos de matrícula extranjera, son sencillos en vista a que se cumple bajo los principios de la eficacia y la eficiencia, sin la necesidad de trámites excesivos o inoperantes para la consecución de la autorización de internación. Lo anterior no quiere decir que la internación vehicular es un trámite sencillo, ya que, gran parte de los documentos que se requieren por parte de la administración nacional son expedidos por los países vecinos. En el caso de la ciudad de Cúcuta este proceso es más complejo por el cierre fronterizo que se presenta desde hace tiempo entre Colombia y Venezuela.

Rodríguez Barriga (2019) también expone que en Cúcuta, se ha ido generando un incremento 
Año 16, Vol. 11, número 21, agosto-diciembre Sección: Dossier

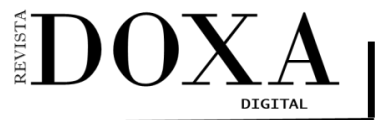

pISSN: 2395-8758 eISSN: 2594-2786
DOI: $10.52191 /$ rdojs.2021.237

Pág.:195-211
Cynthia Ivonne Quiñones Pacheco y

Ignacio Camargo González

Circulación de vehículos con placas informales...

del parque automotor con placas venezolanas, estos vehículos han ocasionado problemas de movilidad, contaminación auditiva, afectación al medio ambiente y al comercio de vehículos nacionales; estos vehículos, transitan exentos de algunas normas y leyes de tránsito que ayudan al control vehicular, puesto que no hay una base de datos que permita la identificación total de estos vehículos, además, el aporte de tributo de estos vehículos es cero y, no contribuyen con los impuestos que permitan la inversión y reparaciones adecuadas de la malla vial, la inversión en infraestructuras y demás proyectos pertinentes de movilidad, además de afectar el sector comercial, pues, al ser vehículos a tan bajo costo, son más asequible que un vehículo nacional afectando, el comercio de automóviles en la ciudad.

La circulación del parque automotor de procedencia venezolana, es un problema público para los entes territoriales, donde no existe un consenso para diseñar políticas públicas para frenar esta problemática que afecta el comercio en general al no pagar impuestos, que se requieren para la inversión en infraestructura.

No se logró la caracterización del parque automotor de procedencia venezolana, dado que no existe un censo de los mismos, por el no acatamiento de las leyes y regulaciones vigentes, por la ilegalidad y el contrabando de este tipo de vehículos que afecta las empresas de comercialización de vehículos colombianos o importados.

Arauz Rivandeneira (2015) recopila datos del año 2013, 2014, 2015, en donde el ingreso de vehículos de uso privado con turistas a territorio ecuatoriano, ha ido aumentando cada año, debiendo tomar en cuenta varios aspectos como: la cercanía entre los dos países, la atracción turística que tienen los ciudadanos colombianos para visitar y descubrir nuevos lugares, la experiencia única que le permite al visitante en poco tiempo experimentar el cambio climático y conocer a fondo las regiones naturales de la sierra, costa, oriente, destacando como factor importante su infraestructura, gastronomía, naturaleza, y el don de gente de sus habitantes.

El régimen de Excepción "Vehículo de Uso Privado del Turista”, permite el ingreso de vehículos de uso privado que van a ser utilizados por ciudadanos extranjeros en actividades de turismo y que ingresan por la frontera terrestre entre Ecuador y Colombia, Puente Internacional de Rumichaca.

\section{Placas informales en Ciudad Juárez}

Dicha identificación vehicular no oficial, fue iniciativa de los loteros y vendedores de autos seminuevos, así como también de las empresas afiliadoras de vehículos usados, para tener un censo o "control" de los vehículos sin registro, dicha situación se derivó por la publicación de un decreto federal que solamente permitía que sean regularizados automóviles a partir del año 2008. Pero dicho apoyo o regulación se ha salido de control, toda vez que hay automóviles que pueden ser importados y contar con placas metálicas expedidas por la autoridad competente, pero por alguna razón siguen circulando ilegalmente.

\section{$\underline{\text { Clientelismo }}$}


Año 16, Vol. 11, número 21, agosto-diciembre Sección: Dossier

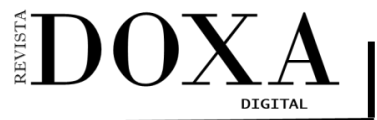

pISSN: 2395-8758 eISSN: 2594-2786
DOI: 10.52191/rdojs.2021.237

Pág.:195-211
Cynthia Ivonne Quiñones Pacheco y

Ignacio Camargo González

Circulación de vehículos con placas informales...

La afiliación de los vehículos extranjeros a las empresas que se dedican a estas actividades, es una acción lucrativa, en la cual encuadra el fenómeno del clientelismo, Audelo Cruz (2004) define al clientelismo como aquellas relaciones informales de intercambio recíproco y mutuamente benéfico de favores entre dos personas, originadas o basadas en amistad, desigualdad, diferencia de poder y control de recursos, en las que existe un patrón y un cliente, el patrón proporciona bienes, protección y acceso a diversos recursos, y el cliente ofrece a cambio servicios personales y lealtad. En México el clientelismo es una práctica cotidiana y normal.

Por otro lado, según Rodríguez Alonso (2019) el clientelismo político es identificado como una relación de intercambio de diversos bienes o servicios o cambio de apoyo político, caracterizado por ser una relación desigual, donde el agente que tiene poder tiene ventaja de negociación y podrá dominar al que posee menor poder, esta relación tiene una duración según as necesidades que las partes tienen para establecerla.

Aunado a lo anterior Acuña Chaverri (2009) afirma que el clientelismo político se ha convertido en un medio para sacar provecho, y, en consecuencia, en perjuicio del Estado de derecho y la democracia en general.

Desde la época de los setenta, se empieza a estudiar el clientelismo político con dos enfoques que se anteponían el uno al otro. El primero lo veía como un adelanto en el desarrollo político. Pretendía conectar el medio con la periferia, cooperando con el crecimiento de la conciencia política en ámbitos donde la participación era limitada. El clientelismo hacía que las élites del centro buscaran conseguir el apoyo de los líderes comunales de la periferia, ofreciendo más y mejores oportunidades, ayudando con el desarrollo de la región y vinculando a las comunidades. Asimismo, los líderes creaban sus alianzas y estos le retribuían al centro manteniendo su base y procurando el control de la región.

Siguiendo los pasos del clientelismo se forma la red clientelar, la cual de acuerdo con Leonidas Aguirre (2012) es un conjunto de actores vinculados a través de una relación que conforman una estructura de relaciones que los dota de posiciones y roles funcionalmente diferenciables, patrones, mediadores y clientes, y configura pautas de interacción que condicionan sus acciones y preferencias dentro de ella, situación que sucede entre quienes expiden las placas informales y los ciudadanos que las compran.

\section{Grupos de presión}

La lucha por influir en el proceso de toma de decisiones hace que estos grupos, denominados grupos de presión, centren su atención en la conducta del aparato gubernamental. Es del Estado, y desde la sociedad civil, donde los grupos ejercen o tratan de ejercer la defensa de sus intereses.

El modus operandi de los grupos adquiere un carácter no formal, invisible, casi secreto. Es cierto que no todas sus actividades son ilícitas; sin embargo, por su propia forma de operar escapan al control de los gobiernos (Díaz Müler 1986), lo manifestado con anterioridad describe el motivo por el cual las empresas afiliadoras de vehículos no importados legalmente siguen de pie, expi- 
Año 16, Vol. 11, número 21, agosto-diciembre

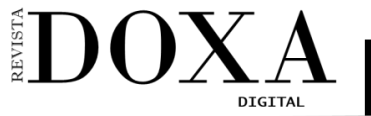

pISSN: 2395-8758 eISSN: 2594-2786
Sección: Dossier

DOI: 10.52191/rdojs.2021.237

Pág.:195-211
Cynthia Ivonne Quiñones Pacheco y

Ignacio Camargo González

Circulación de vehículos con placas informales...

diendo las placas informales.

Bouzas (2012) en su texto afirma que existen ciertos grupos formados por individuos con intereses comunes que sin deseo de estar en el gobierno, ejercen presión sobre el estado para obtener decisiones favorables a sus intereses; es necesario conocer la forma como estos grupos actúan y la posibilidad que tienen de conseguir sus prop6sitos, sobre todo en el caso en el que la acci6n de los grupos de presi6n rebase un determinado marco nacional y se sitúe a nivel internacional, en donde hay pocas restricciones al uso de la fuerza, de modo que del estudio que al respecto se realice podamos obtener respuesta a preguntas como estas: forma, intensidad, alcances y efectividad de la presión ejercida por los grupos.

Los grupos de presión existen alrededor de todo el mundo y tienen distintas formas en las cuales se les denomina, un ejemplo es lo escrito por Pineda Cachero (2002), el mismo menciona que según la Enciclopedia Británica, lobbying (o cabildeo político, en español) es "cualquier intento por parte de individuos o grupos de intereses privados para influir en las decisiones del gobierno.

Otras visiones del fenómeno resaltan el hecho de que el lobby es una agencia independiente, técnica, al servicio del grupo de presión. Así, los lobbies serían "agencias, gabinetes de comunicación o despachos de abogados, dedicados profesionalmente a ejercer la actividad del lobbying en representación de un grupo de interés o de presión que los contrata", por estas situaciones las empresas que expiden placas informales cuentan con diversos medios legales que los amparan para seguir laborando, promueven defensas ante los tribunales competentes.

\section{Metodología}

\section{Enfoque, alcance y diseño de la investigación}

La investigación es nivel de estudio uno, es local, tendrá un enfoque cualitativo, de tipo exploratorio, no experimental, transversal.

\section{Diseño específico}

El diseño con el que contará la investigación es el fenomenológico, haciendo referencia a lo expuesto por Hernández Sampieri (2014), ya que la fenomenología explora, describe y comprende las experiencias de las personas con respecto a un fenómeno y descubre los elementos en común de las vivencias.

\section{Muestra}

Las entrevistas serán contestadas por voluntarios, que serán personas mayores de edad, hombres y mujeres, propietarios de un vehículo de procedencia extranjera, no legalizado, que porta placas no oficiales.

También serán entrevistados actores claves tomadores de decisiones dentro del fenómeno de las placas informales no oficiales. 
Año 16, Vol. 11, número 21, agosto-diciembre

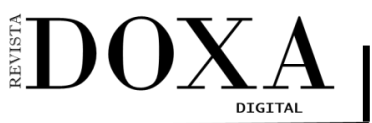

pISSN: 2395-8758 eISSN: 2594-2786
Sección: Dossier

DOI: 10.52191/rdojs.2021.237

Pág.:195-211
Cynthia Ivonne Quiñones Pacheco y

Ignacio Camargo González

Circulación de vehículos con placas informales...

\section{Técnicas de recolección de datos}

Se efectuarán entrevistas semiestructuradas a personas mayores de edad, propietarias de vehículos con placas no oficiales; entrevistas semiestructuradas a vendedores de autos usados y asociaciones afiliadoras que expidieron placas informales; entrevistas semiestructuradas a actores clave tomadores de decisiones; revisión documental en revistas de alto impacto CONACYT y artículos científicos relacionados con el tema a investigar.

\section{Instrumento (cuestionarios)}

Cuestionario para entrevista \#1

- ¿De acuerdo con su experiencia como propietario porqué considera usted que optan por las placas informales o no oficiales?

- ¿De acuerdo con lo que usted sabe, dónde se consiguen estas las placas informales?

- ¿Cuál es el costo que tienen?

- ¿Cuánto duran vigentes estas placas?

- ¿A dónde se va el dinero cobrado por las placas informales?

- ¿Cuáles son los motivos de que se adquieran vehículos con placas informales?

- ¿Conoce usted las sanciones que se aplican a los propietarios de este tipo de vehículos?

- ¿Estas sanciones se aplican? SI ó NO

- ¿Por qué?

- ¿ ¿Considera que existe algún tipo de arreglo entre el gobierno y las asociaciones que expiden estas placas no oficiales?

- ¿QQué sucede cuando la autoridad detiene un vehículo con placas no oficiales?

- ¿QQué ocurre cuando se retira un vehículo con placas informales?

- ¿Por qué?

- ¿Cómo evaden a la autoridad los propietarios de este tipo de vehículos?

- Cuestionario para entrevista \#2

- ¿De acuerdo con su experiencia como agente de vialidad, porqué considera usted que los propietarios de los vehículos optan por las placas informales o no oficiales?

- ¿De acuerdo con lo que usted sabe, dónde se consiguen estas las placas informales?

- ¿Cuál es el costo que tienen?

- ¿Cuánto duran vigentes estas placas? 
Año 16, Vol. 11, número 21, agosto-diciembre

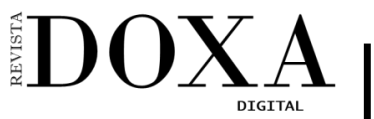

Sección: Dossier

DOI: 10.52191/rdojs.2021.237

Pág.:195-211
Cynthia Ivonne Quiñones Pacheco y

Ignacio Camargo González

Circulación de vehículos con placas informales...

- ¿A dónde se va el dinero cobrado por las placas informales?

- ¿Cuáles son los motivos de que se adquieran vehículos con placas informales?

- ¿Cuáles son las sanciones hacia a los propietarios de este tipo de vehículos?

- ¿Estas sanciones se aplican? SI ó NO

- ¿De qué manera?

- ¿ ¿Considera que existe algún tipo de arreglo entre el gobierno y las asociaciones que expiden estas placas no oficiales?

- ¿Ha participado alguna vez en dichos arreglos?

- ¿Qué sucede cuando se detiene a un vehículo con placas no oficiales?

- ¿Qué ocurre cuando se retira un vehículo con placas informales?

- ¿Por qué?

- ¿Cómo evaden a la autoridad los propietarios de este tipo de vehículos?

- ¿ ¿Ha sido participe de la mencionada evasión?

- Cuestionario para entrevista \#3

- ¿ ¿De acuerdo con su experiencia como vendedor de placas informales porqué considera usted que los propietarios de los vehículos optan por las placas informales o no oficiales?

- ¿Cuáles son los requisitos para adquirir las placas no oficiales?

- ¿Cuál es el costo que tienen?

- ¿Cuánto duran vigentes estas placas?

- ¿A dónde se va el dinero cobrado por las placas informales?

- ¿Cuáles son los motivos de que se adquieran vehículos con placas informales?

- ¿Cuáles son las sanciones hacia a ustedes que venden placas informales?

- ¿Estas sanciones se aplican? SI ó NO

- ¿Por qué?

- ¿Considera que existe algún tipo de arreglo entre el gobierno y las asociaciones que expiden estas placas no oficiales?

- ¿Ha participado alguna vez en dichos arreglos?

- ¿Qué sucede cuando se detiene a un vehículo con placas no oficiales?

- ¿Qué ocurre cuando se retira un vehículo con placas informales? 
Año 16, Vol. 11, número 21, agosto-diciembre

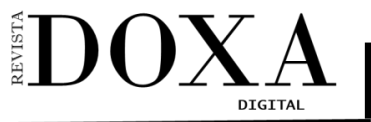

Sección: Dossier

DOI: $10.52191 /$ rdojs.2021.237

Pág.:195-211
Cynthia Ivonne Quiñones Pacheco y

Ignacio Camargo González

Circulación de vehículos con placas informales...

- ¿Por qué?

- ¿Cómo evaden a la autoridad los vendedores de placas informales?

- ¿ ¿Ha sido participe de la mencionada evasión?

- Cuestionario para entrevista \#4

- ¿De acuerdo con su experiencia como funcionario de Hacienda, porqué considera usted que los propietarios de los vehículos optan por las placas informales o no oficiales?

- ¿Cómo se consiguen estas las placas informales?

- ¿Cuál es el costo que tienen?

- ¿Cuánto duran vigentes estas placas?

- ¿A dónde se va el dinero cobrado por las placas informales?

- ¿Cuáles son los motivos de que se adquieran vehículos con placas informales?

- ¿Cuáles son las sanciones hacia los propietarios de autos con placas no oficiales?

- ¿Estas sanciones se aplican? SI ó NO

- ¿Por qué?

- ¿Cuáles son las sanciones hacia los vendedores de placas informales?

- ¿Estas sanciones se aplican? SI ó NO

- ¿Por qué?

- ¿Considera que existe algún tipo de arreglo entre el gobierno y las asociaciones que expiden estas placas no oficiales?

- ¿Ha participado alguna vez en dichos arreglos?

- ¿Qué sucede cuando se detiene a un vehículo con placas no oficiales?

- ¿Qué ocurre cuando se retira un vehículo con placas informales?

- ¿Por qué?

- ¿Cómo evaden a la autoridad los vendedores de placas informales?

- ¿ ¿Ha sido participe de la mencionada evasión?

Técnicas de análisis de datos

La técnica cualitativa de análisis de datos será narrativa.

\section{Resultados esperados}


Sección: Dossier

DOI: $10.52191 /$ rdojs.2021.237

Pág.:195-211
Cynthia Ivonne Quiñones Pacheco y

Ignacio Camargo González

Circulación de vehículos con placas informales...

Se esperan conocer los motivos por los cuales existe la compra-venta de automóviles de procedencia extranjera con placas informales no oficiales, conocer si existe y cómo es la relación de poder que permite este fenómeno social, los motivos por los cuales no se aplica la política pública que corresponde a las placas informales.

\section{Referencias}

Acuña Chaverri, I. A. (2009). Elementos conceptuales del clientelismo político y sus repercusiones en la democracia. Reflexiones 88 (2), 27-36.

Alarcón Gil, C. (2014). Ciudad Juárez: Sociedad, criminalidad y violencia transnacional. En A. M. Jaramillo, Ciudades en la encrucijada: violencia y poder criminal en Río de Janeiro, Medellín, Bogotá y Ciudad Juárez (pág. 249). Medellín, Colombia: Corporación Región.

Aller Vera, R. L.(2016). La incautación de vehículos por presunto delito de contrabando y la vulneración del derecho de propiedad. Tesis de licenciatura no publicada, Universidad Andina del Cusco, Cusco, Perú.

Álvarez del Campo, I. (2019). Influencia del parque vehicular en los requisitos de ventilación de túneles.Tesis de ingenieria no publicada. Universidad de Cantabria, Cantabria, España.

ANAPROMEX. (2021). Recuperado de https://anapromex.com.mx/

Anguamea Martínez, M. T. (2019). Legitimación y Permanencia Organizaciones Afiliadoras de Vehículos de Procedencia Extranjera en Sonora, 2004-2019. Tesis de maestria no publicada. El Colegio de Sonora, Hermosillo, Sonora, México

Anónimo. (2020). Origen de las placas rojas. (C. I. Quiñones Pacheco, Entrevistador)

Arauz Rivadeneira, J. A. (2015). El regímen de excepción "vehículo de uso privado del turista" y su aplicación en la frontera entre Ecuador y Colombia. Comercio \& negocio, (No. 5), 33-42.

Arévalo Avecillas, D. y. (2009). Proyecto de sostenibilidad financiera de una concesionaria de vehículos usados. Ecuador.

Aruquipa Suntura, F. (2012). Procedimientos de inspección técnica de los códigos alfanumericos de chasis y/o número de indentificación del vehículo (V.I.N.).Tesis de licenciatura no publicada.Universidad Mayor de San Andrés. La Paz, Bolivia.

Audelo Cruz, J. M. (2004). ¿Qué es el clientelismo? Algunas claves para comprender la política en los países en vías de consolidación democrática. Estudios Sociales, 12 , 124-142.

Barrera-Enderle, A. (2018). Aduanas, poderes locales y contrabando de automóviles. El desafío al Estado-Nación desde la frontera noreste, 1920-1960. Humanitas, 4, (No. 45), 9-44.

Bernal Saavedra, S. J. (2005). Regularización impositiva de adeudos tributarios de vehículos indocumentados. Tesis de diplomado no publicada. Universidad Mayor de San Andrés, La Paz, Bolivia. 
Sección: Dossier

DOI: $10.52191 /$ rdojs.2021.237

Pág.:195-211
Cynthia Ivonne Quiñones Pacheco y

Ignacio Camargo González

Circulación de vehículos con placas informales...

Bouzas, A. (2012). México: los grupos de presión. Lorenzo Meyer. Problemas del Desarrollo. Revista Latinoamericana de Economía, 6, (No. 25), 144-146.

Castro Cobo, M. J. (2014). Investigación de la legalidad y cumplimiento tributario en la compra venta de vehículos usados en el Ecuador. Tesis de maestría no publicada. Universidad Andina Simón Bolivar. Quito, Ecuador.

Chihuahua, E. d. (2020). Gobierno del Estado de Chihuahua. Vehículos sin placas oficiales serán retirados por los tres órdenes de Gobierno en Juárez. Recuperado de: http:// www.chihuahua.gob.mx/contenidos/vehiculos-sin-placas-oficiales-seran-retirados-por-los-tresordenes-de-gobierno-en-juarez

Chipix Notz, M. R. (2014). Estudio administrativo de una empresa importadora de vehículos usados tipo sedan, pick up y de doble tracción. Tesis de maestría no publicada, Universidad de San Carlos Guatemala, Guatemala.

Cruz-Rivera, R. y Ertel, J.. (2008). Acumulación de productos al final de su vida útil en México, el caso de los vehículos automotores. Revista Internacional de Contaminación Ambiental 24 (3), 117-130.

Cuito Freire, A. V. (2014). La importación de autos y su impacto en el mercado informal de venta de autos usados en la feria de Ambato. Tesis de licenciatura no publicada. Universidad Técnica de Ambato. Ambato, Ecuador.

Díaz Müler, L. (1986). Grupos de presión y derechos humanos. Revista mexicana de sociología, 48, (No. 3), 253-271.

Escalante Olarte, M. Y., y Hernández Santiago, D. Y. (2018). Viabilidad jurídica de la internación temporal de vehículos de matrícula venezonala en el municipio de San José de Cúcuta como zona de frontera con el estado de Táchira. Tesis de licenciatura no publicada. Univeridad Libre Seccional Cúcuta.

Escalante Olarte, M. Y., y Hernández Santiago, D. Y. (2018). Viabilidad jurídica de la internación temporal de vehículos de matrícula venezonala en el municipio de San José de Cúcuta como zona de frontera con el estado de Táchira. Tesis de licenciatura no publicada. Univeridad Libre Seccional Cúcuta. Cúcuta, Colombia.

Favia, L. (2020). Yo Ciudadano. Parque vehicular en aumento, una problemática ambienta. Recuperado de https://yociudadano.com.mx/noticias/parque-vehicular-en-aumento-unaproblematica-ambiental/

Fiscalia General del Estado. (2021). Registro Público Vehicular (REPUVE). Recuperado de: http:// fiscalia.chihuahua.gob.mx/inicio/?page_id $=128$

Gutierrez, R., y Frydson, M. F. (2011). Aplicacion de visión por comútador para el reconocimiento automático de placas vehiculares utilizado OCR's convencionales. Ecuador. 
Sección: Dossier

DOI: $10.52191 /$ rdojs.2021.237

Pág.:195-211
Cynthia Ivonne Quiñones Pacheco y

Ignacio Camargo González

Circulación de vehículos con placas informales...

Huerta de Ávila, E. (2014). Control Vehicular en México: El programa del Registro Público Vehicular. Buen Gobierno, 16, 146-156.

INSTITUTO NACIONAL DE ESTADÍSTICA Y GEOGRAFÍA. (2021). Recuperado de https:// www.inegi.org. $\mathrm{mx} /$

Leonidas Aguirre, J. (2012). Redes clientelares. Una perspectiva teórica desde el análisis de redes sociales. Documentos de Trabajo, 83, CIEPP, Buenos Aires, Argentina.

López Gutiérrez, P. (2015). Del comercio informal y los espacios públicos. La brújula, Nexos.

López Torres, V., y Moreno Moreno, L. R. (2015). Comercio informal: un caso en Ensenada, Baja California. Gestión y Estrategia: Organizaciones Teoría y Casos, 47, 49-60

Machuca Segovia, F. A. (2013). Proceso a seguir para la matriculación obligatoria de vehpiculos particulares en el Cantón Cuenca. Tesis de ineniería no publicada. Universidad del Azuay, Cuenca, Ecuador.

Márquez Ramírez, C. A. (2011). Impacto generado por la ley 1383 de 2010 que modifica la ley 769 de 2002, en relación con las sanciones por infracciones de tránsito en el Valle de Aburrá. Tesis de maestría no publicada. UniversidaEAFIT, Medellín , Colombia.

Martínez Rodriguez, M. C., y Kuppusamy, I. y. (2006). Legalización de los autos chocolate, políticas públicas vs impacto ambiental. Calidad Ambiental, vol 11, No. 2, 10-13.

Merchán Galarza, P. J. (2018). Efectos de las restricciones aduaneras de importaciones, vehículos en Guayaquil, año 2012 al 2016. Tesis de ingenieria no publicada, Universidad de Guayaquil, Ecuador.

Ollivier Fierro, J. Ó. (2018). El destino final de los vehículos automotores. Un problema ambiental poco tratado en Chihuahua, México. Excelencia Administrativa, 46, 41-60.

ONAPPAFA, A.C. (2021). Recuperado de http://onappafa.net/info.php

Parra, P. (2015). El negocio de autos usados, víctima del efecto dominó. Empresarial (I) Gestión, $255,48-51$.

Pineda Cachero, A. (2002). Lobbies y grupos de presión: de la políticaa a la comunicación. Una fundamentación teórica. Laurea Hispalis: Revista internacional de investigación en relaciones públicas, cereminial y protocolo, 1, 87-122.

Quimbita Tercero, R. M. (2016). Análisis del mercado de vehículos usados y su comercialización en el Distrito Metropolitano de Quito considerando la asimetría de información entre compradores y vendedores. Tesis de licenciatura no publicada, Pontificia Universidad Católica del Ecuador, Quito, Ecuador.

Quintanilla Madero, C. (2021). Diario Oficial de la Federación. Obtenido de Norma Oficial Mexicana NOM-131-SCFI-1998, Determianción, asignación e instalación del número de indentificación 
Sección: Dossier

DOI: $10.52191 /$ rdojs.2021.237

Pág.:195-211
Cynthia Ivonne Quiñones Pacheco y

Ignacio Camargo González

Circulación de vehículos con placas informales...

vehicular-Especificaciones. Recuperado de http://www.dof.gob.mx/nota_detalle.php? codigo $=4886072 \&$ fecha $=06 / 07 / 1998$

Ramirez Castillo, G. V. (2017). El mercado informal de la compra/venta de vehículos usados en ferias y patios de la provincia de Pichincha. Tesis de maestría no publicada. Universidad Andina Simón Bolivar. Quito, Ecuador

Ramírez López, L. y. (2013). Crecimiento económico, corrupción e instituciones en México. Nóesis, Revista de ciencias sociales y humanidades,22, (No. 43), 104-133.

Rodríguez Alonso, J. A. (2019). Clientelismo político: un acercamiento al caso del estado de Chihuahua y Sinaloa. En J. E. En A. Paniagua Vázquez, J. E. Borunda Escobedo e I. Camargo-González (Ed.), La encrucijada de la democracia en México: visión desde la región Paso del Norte (pp. 88). Ciudad Juárez, México: Departamento de Publicaciones, El Colegio de Chihuahua.

Rodriguez Barriga, D. A. (2019). Caracterización del impacto generado por los vehículos venezolanos en el centro de Cúcuta. Tesis de licenciatura no publicada, Universidad Libre de Colombia, San José Cúcuta, Colombia.

Rodriguez Barriga, D. A. (2019). Caracterización del impacto generado por los vehículos venezolanos en el centro de Cúcuta. Tesis de licenciatura no publicada, Universidad Libre de Colombia, San José Cúcuta, Colombia.

Salinas Galarza, A. M. (2014). Impacto de la importación de autos usados según D. S. 29836 en las casas importadoras (2000-2012) caso La Paz. Tesis de licenciatura no publicada. Universidad Mayor de San Andrés, La Paz, Bolivia.

Tovar, H. (2020). Van 300 autos sin placas decomisados. El Heraldo de Juárez. Recuperado de https://www.elheraldodejuarez.com.mx/local/van-300-autos-sin-placas-decomisados-noticiasde-ciudad-juarez-5786275.html

Urbina Ortíz, V. (2009). Impacto de los automoviles usados de procedencia extranjera ilegal al cambio climatico en el municipio de San Luis Potosí y zona concurbada. Tesis de licenciatura no publicada, Universidad Autónoma de San Luis Potosí, San Luis Potosí, México.

Urbizu-González, A. L., Andrade-Limas, E. d., De la Garza-Requena, F. R.,y\& Macias-Hernández, B. A.-E. (2014). Incremento vehicular y estimación de las emosiones a la atmósfera de vehículos de motor en Victoria, Tamaulipas. TecnoINTELECTO, órgano de divulgación científica, 11, (No. 1), 34-41

Vargas, M. (2020). Autos "chuecos". El diario de Juárez, https://diario.mx/juarez/escondenpropietarios-sus-autos-chuecos-20200901-1703597.html

Vivas Paguatin, K. A. (2020). La finalidad sancionatoria de la multa. Santiago de Cali. Trabajo de diplomado no publicado. Universidad de Santiago de Cali, Cali, Colombia. 